\title{
Porphyromonas catoniae
}

National Cancer Institute

\section{Source}

National Cancer Institute. Porphyromonas catoniae. NCI Thesaurus. Code C86655.

A species of obligately anaerobic, Gram-negative, rod shaped bacteria assigned to the phylum Bacteroidetes. This species is nonmotlie, non-spore forming, indole positive, produces major amounts of propionic acid, liquefies gelatin, hydrolyzes starch, but not esculin, and does not reduce nitrate. P. catoniae has been isolated from the gingiva of healthy individuals as well as from those with ging ivitis or periodontal disease. 